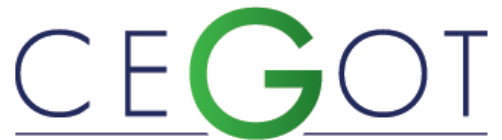

Centro de Estudos de Geografia e Ordenamento do Território

Geografia e Ordenamento do Território, Revista Eletrónica Centro de Estudos de Geografia e Ordenamento do Território http://cegot.org

CUNhA, EgLAISA

Universidade do Estado de Santa Catarina, Centro de Ciências Humanas e da Educação - FAED/CICS.Nova

71070-640, Brasília, Brasil (Área Especial 4 Módulo G/H, BI. B, Apto.1403.

Guará II-DF)

eglaisa@gmail.com

\author{
OliveIRA, FRANCISCO \\ Universidade do Estado de Santa Catarina, Centro de Ciências \\ Humanas e da Educação - FAED \\ 88035-901, Florianópolis-SC, Brasil \\ chico.udesc@gmail.com \\ JULIÃO, RUI \\ Universidade Nova de Lisboa, Faculdade de Ciências Sociais e \\ Humanas/CICS.NOVA \\ 1069-061, Lisboa, Portugal \\ rpi@fcsh.unl.pt \\ CARneiro, ANDREA \\ Universidade Federal de Pernambuco, Centro de Tecnologia, \\ Departamento de Engenharia Cartográfica \\ 52060-110, Recife-PE, Brasil \\ andreaftenorio@gmail.com
}

\title{
O cadastro urbano no Brasil: histórico e evolução
}

The urban cadastre in Brazil: history and evolution

Referência: Cunha, Eglaisa et al. (2019). O cadastro urbano no Brasil: histórico e evolução. Revista de Geografia e Ordenamento do Território (GOT), n. ${ }^{\circ} 17$ (junho). Centro de Estudos de Geografia e Ordenamento do Território, p. 55-74, dx.doi.org/10.17127/got/2019.17.003

\section{RESUMO}

Este artigo aborda o percurso histórico e a evolução da implementação do cadastro territorial urbano no Brasil. Parte-se do pressuposto de que a sua evolução está diretamente ligada à dinâmica do processo de municipalização e de ocupação territorial do país, ampliado a partir da Constituição de 1946. O Projeto CIATA, nas décadas de 1970/80, é apresentado como a primeira iniciativa que formula uma metodologia nacional e conduz a implementação de cadastros urbanos. Registram-se, ainda, outras iniciativas governamentais de apoio financeiro à implementação de cadastros urbanos, bem como o cenário que se conforma a partir da Constituição de 1988, do Estatuto da Cidade e da criação do Ministério das Cidades, que publica, em 2009, as diretrizes para a elaboração do cadastro territorial urbano, sob a perspectiva multifinalitária.

Palavras-chave: Cadastro Territorial Mulfinalitário, Cadastro Urbano, CIATA, Diretrizes para o CTM. 


\section{ABSTRACT}

This paper discusses the historical course of the urban territorial cadastre and the evolution of its implementation in Brazil. It is assumed that its evolution is directly connected to the dynamics of the municipalization and territorial occupation of the country, which has started based on the Constitution of 1946. CIATA Project in the 1970s and 1980s is presented as the first initiative that formulates and centrally steers a national methodology for the implementation of urban cadastres. It is also presented government initiatives to provide financial support for the implementation of urban cadastres, as well as the context of urban policy since the approval of the Constitution of 1988, the City Statute, and the creation of the Ministry of Cities, which approved in 2009, the guidelines for the elaboration of the urban territorial cadastre, with a multipurpose perspective.

Keywords: Multipurpose Cadastre, Urban Cadastre, CIATA, Guidelines to the CTM.

\section{Introdução}

A implementação do Cadastro urbano no Brasil pode ser compreendida a partir da dualidade e da dinâmica do processo histórico de ocupação territorial do país e do seu processo de municipalização.

No âmbito rural, as políticas governamentais adotadas desde o momento de colonização e povoamento do território e respectivas legislações que se seguiram, fundamentam as bases da atual estrutura agrária no Brasil, baseada no latifúndio, e justificam as características legais do cadastro rural que é realizado de forma sistemática e centralizada no âmbito do governo federal, por meio do Instituto Nacional de Colonização e Reforma Agrária - INCRA, nos termos da Lei $n$ o $10.267 / 2001$.

No caso do cadastro urbano, o acelerado processo de urbanização e municipalização do país dos últimos 50 anos revela a sua diversidade e complexidade, agravadas pela ausência de regulamento nacional. Neste artigo, aborda-se o percurso histórico do cadastro urbano no Brasil e a sua evolução sob o ponto de vista de sua implementação progressiva nos municípios brasileiros e regulamentação nacional (Ver Quadro 1: O Cadastro Urbano no Brasil - Linha do Tempo). 


\section{O processo de municipalização e as primeiras experiências de}

\section{cadastro urbano}

Embora o processo de municipalização do Brasil tenha sido lento e gradual no início do século $X X$, ele se intensifica a partir do processo de autonomia municipal designado progressivamente na legislação nacional, cujo início se pauta no âmbito da Constituição de 1946. Neste marco legislativo, o conceito de peculiar interesse municipal é resgatado por meio da deliberação sobre a arrecadação dos tributos como competência local, de forma a dar maior liberdade à administração municipal para organizar os serviços públicos locais. Além disso, garantiu a eleição dos prefeitos, estabelecendo uma noção comum entre autonomia administrativa e autonomia política e instituiu também o mecanismo de participação na arrecadação da União e dos estados, que originou o Fundo de Participação Municipal - FPM (Cigolini, 2009).

Desse modo, a partir dos novos preceitos constitucionais de 1946, há um considerável aumento no número de municípios no Brasil, que passam, por consequência, a se organizar para a cobrança dos tributos, em especial o IPTU - Imposto Predial Territorial Urbano, sendo este o ponto de partida para a organização dos primeiros cadastros fiscais imobiliários.

Segundo Cigolini (2009), entre 1946 e 1964, foram criados um total de 2.221 municípios, com uma média de 117,20 por ano, muito superior aos períodos anteriores (média de 18, de 1931 a 1945, e de 13 por ano, de 1890 a 1930). A malha municipal brasileira, ao final desse período, havia sofrido acréscimo de $134 \%$ sobre o total dos municípios existentes anteriormente.

Na década de 50 surgem, então, as primeiras experiências de cadastro técnico urbano, com o objetivo de modernização e controle do IPTU. Segundo Carneiro (2003), tais experiências se iniciaram com o Grupo Hollerith, na cidade de Curitiba (Anoter/Funcate, 1997, apud Carneiro, 2003), que introduziu a metodologia fotogramétrica no cadastramento de campo, com a utilização de base cartográfica para ampliar as fotografias aéreas de todas as unidades urbanas tributáveis territoriais/prediais, na escala 1:1.000. Segundo relatos, essa empresa utilizou essa mesma metodologia em cerca de 40 cidades brasileiras. 
Em 1964, a legislação decorrente do Golpe Militar no Brasil inaugurou uma nova tendência de centralização de poder, em detrimento dos poderes locais e regionais, de forma a restringir, por consequência, a autonomia municipal. Muitos municípios que estavam em processo de emancipação foram extintos e uma nova estratégia geopolítica de ocupação do território foi utilizada, uma vez que o poder central fez das fronteiras municipais um dos elementos de integração regional. Segundo Cigolini (2009), isso se demonstra pela Lei Complementar publicada no ano de 1967, que normatizou as regras para a emancipação municipal: embora os estados se mantivessem como responsáveis pela criação de municípios, exigia-se que populações superiores a 10.000 habitantes ou não inferior a 5 milésimos da existente no estado.

Por outro lado, com o rápido aumento da população urbana nos anos 50 e 60, os serviços urbanos, principalmente o da habitação, não conseguem atender as necessidades da sociedade e demandavam estruturas de governo que pudessem dar o devido suporte e a atenção necessária para o problema que se agravava.

Nesse contexto, a Lei no 4.380/1964 cria o Banco Nacional de Habitação - BNH e institui também o Serviço Federal de Habitação e Urbanismo - SERFHAU, cujas atribuições compreendiam desde promover pesquisas e estudos relativos ao déficit habitacional, aspectos do planejamento físico, técnico e socioeconômico da habitação, até assistir os municípios na elaboração ou adaptação de seus planos diretores, sendo que esta última função foi reforçada por meio de uma reformulação de suas atribuições ocorrida em 1967, o que transformou o SERFHAU num instrumento de apoio ao planejamento urbano e local no Brasil.

Na prática, segundo Vizioli (1998), houve uma dependência do SERFHAU em relação ao $\mathrm{BNH}$, na qual para receberem financiamentos do $\mathrm{BNH}$, os municípios deveriam possuir um Plano de Desenvolvimento Local Integrado, executado de acordo com a metodologia desenvolvida pelo SERFHAU.

Segundo Souza (apud Vizioli, 1998: 77), os planos sob a supervisão do SERFHAU não eram apenas físico-territoriais: "Para beneficiar a cidade e a sociedade, era preciso instituir um sistema de Planejamento composto por 3 partes: a sua institucionalização no campo da 
Prefeitura, a preparação do pessoal técnico para levar adiante o planejamento e a implementação de um cadastro técnico municipal."

Por meio dessas premissas, e pelas deficiências na obtenção de dados básicos espaciais para o planejamento (Carneiro, 2003), o SERFHAU passa a financiar, com recursos do BNH, o Cadastro Técnico Municipal de médias e grandes cidades do país. Na época, o SERFHAU chegou a cadastrar mais de duzentas empresas que se habilitavam a participar de concorrências públicas em todo o país para a execução do Cadastro Técnico Municipal.

\section{Evolução do cadastro urbano no Brasil}

Infere-se que foi a partir do apoio da SERFHAU/BNH que o Cadastro urbano começa a ser implementado nos municípios brasileiros, embora nem sempre como uma experiência bem sucedida, devido à ausência de um marco normativo nacional que pautasse a sua implementação de forma estruturante e eficaz.

\subsection{O Projeto CIATA}

Na década de 1970, para que os pequenos municípios também tivessem a possibilidade de implantar o Cadastro Técnico Municipal, surge o Projeto CIATA - Convênio de Incentivo ao Aperfeiçoamento Técnico - que foi implantado, de forma experimental (1973/74), pela Secretaria de Economia e Finanças do Ministério da Fazenda do Brasil, com recursos do Programa de Assistência Técnica - PRAT e, por meio do Serviço Federal de Processamento de Dados (Serpro).

Segundo documentos e manuais produzidos pelo Serpro/Ministério da Fazenda à época, o Projeto CIATA foi desenvolvido para ser executado mediante a ação conjunta e conveniada entre os três níveis de governo (federal, estadual e municipal), para constituir um sistema dinâmico de coleta e tratamento de informações, tendo como meta o aperfeiçoamento técnico-administrativo do município, por meio da elaboração de um Cadastro Técnico Urbano (CTU). Trata-se da primeira iniciativa formal de estruturação metodológica do 
cadastro urbano pelo governo federal, iniciativa que balizou a estruturação e implementação do cadastro imobiliário na maioria dos municípios brasileiros.

Inicialmente, o Projeto foi desenhado para contemplar "pequenos municípios", ou seja, aqueles que à época tivessem, aproximadamente, 3.000 unidades imobiliárias em sua sede.

Para desenvolver a metodologia do Projeto, com vistas ao fornecimento de assistência técnico-administrativa aos pequenos municípios, foi desenvolvida uma pesquisa à época (Brasil, 1980), por meio de amostra de 21 municípios situados na Região Nordeste, Sudeste e Sul do país (Pernambuco: Ipojuca, Sirinhaém, Tracunhaém. Alagoas: Maragogi, Coqueiro, Satuba, Santa Luzia do Norte. Minas Gerais: São Francisco do Glória, Caiana, B. do Monte Alto, Patrocínio do Muriaé, Eugenópolis, Antonio Prado, Laranjal, Vieiras, Miradouro. Santa Catarina: São João Batista, Ascurra, Garopaba, Rodeio, Botuverá e Águas Mornas), tendo sido o critério de proximidade, concentração e rapidez de acesso aos municípios que balizaram a escolha destes. Utilizou-se um formulário para o levantamento de aspectos referentes à estrutura formal e informal das prefeituras, sistemas de avaliação de imóveis, arrecadação etc.

No que se refere ao perfil relativo ao método de cadastro empregado, constatou-se que a organização do cadastro imobiliário se dava geralmente de forma semelhante entre os municípios pesquisados, com fichas próprias, de diferentes formatos e conteúdos, sendo observada maior padronização nos municípios da região sul, tendo em conta a interferência das Associações de Municípios ou de consultorias técnicas.

Constatou-se, no entanto, que a atualização do cadastro era diferenciada nas Regiões da seguinte forma: nas regiões Nordeste e Sudeste a atualização ocorria somente quando da compra e venda de imóveis, sendo que o controle dos cadastros era bastante precário e com baixo grau de confiabilidade. Na região Sul, apesar do apoio das Associações, a atualização ocorria por meio de informações muito básicas, tais como endereço, proprietário e, às vezes, as medidas dos imóveis. Em geral, não havia uma rotina de atualização cadastral, o que só ocorria à medida em que houvesse interesse por parte do contribuinte.

Com a realização da pesquisa e a constatação de variações acentuadas no grau de desenvolvimento socioeconômico dos municípios das Regiões Sul e Sudeste em relação à 
Região Nordeste, destacou-se a importância de se conceber o Programa de forma a atentar para as desigualdades inter e intra regionais no que refere à capacidade de absorção metodológica do Projeto, às necessidades técnicas específicas de cada município, bem como ao padrão diferenciado dos imóveis nas referidas regiões.

Outra conclusão interessante do estudo realizado pela equipe do Projeto Ciata foi a de que quanto menor o porte dos municípios, menor o interesse das Prefeituras em aumentar suas receitas próprias, em função do muito pouco que representam ou poderiam representar em relação às transferências de outros níveis de governo e, principalmente, em função de elevado custo político que tal medida acarretaria às prefeituras que mantém, dentro do reduzido tamanho do município, um relacionamento predominantemente informal com os contribuintes. Já em outros municípios, onde o potencial contributivo era maior, verificouse um interesse em instrumentos eficazes para efeitos de tributação.

A desorganização administrativa generalizada também foi apontada como uma consequência e não a causa dos baixos índices de arrecadação advinda dos tributos municipais, o que fez com que o Projeto fosse fundamentado pela importância de se dar maior simplicidade aos instrumentos e técnicas empregadas, primando pela formação do quadro técnico municipal e pela importância de se motivar os contribuintes quanto à importância dos tributos municipais: "Sem o incremento do fator motivação, mesmo os mais adequados instrumentos utilizados e até mesmo por pessoal treinado tende a cair em desuso em pouco tempo, sendo substituídos pelos antigos, com as rotinas até então empregadas pelas municípios" (Brasil, 1980).

Com o andamento do Projeto e, tendo em conta a necessidade de desenvolvimento e/ou expansão determinadas pelos governos estaduais, o projeto foi sendo implantado de forma gradativa em municípios de maior porte, sendo que a partir do período de 1976/1977, qualquer município poderia se candidatar ao Projeto.

De um modo geral, a proposta do Projeto CIATA foi a de criar um sistema de cadastros técnicos que de "forma lógica, justa e eficiente" pudesse promover o aumento das receitas próprias do município, de forma a diminuir sua dependência em relação aos recursos externos. 
A concepção "Modular" do Projeto procurou dar a flexibilidade necessária para o atendimento individualizado das necessidades de cada município, no que se refere ao número de informações necessárias a serem coletadas, a sua forma de tratamento, o grau de assistência jurídica e administrativa e até mesmo a estratégia de execução dos trabalhos. $\mathrm{Na}$ época, verificou-se que não havia necessidade de processamento eletrônico para os municípios de pequeno porte devido à quantidade de informações e à forma de tratamento.

De acordo com a referida concepção, cinco módulos formaram a base de implementação do projeto: I - Assistência Jurídica, II - Assistência Administrativa, III - Cadastro Imobiliário Urbano, IV - Cadastro Fiscal Mobiliário e V - Receita, sendo que estes três últimos poderiam até não ser executados de uma só vez, o que dependeria da solicitação e das necessidades de cada Prefeitura, evidenciando-se aqui o caráter de flexibilidade característico do Projeto CIATA.

No que se refere ao Cadastro Imobiliário Urbano (Módulo III), o projeto o definia como "um conjunto de informações da área urbana que são levantadas e devem ser mantidas permanentemente atualizadas pelas municipalidades. Essas informações referem-se aos imóveis urbanos, valores dos imóveis, identificação dos contribuintes, obras públicas e particulares, serviços urbanos e ocupação do espaço urbano".

Desse modo, as informações deveriam ser registradas por unidade imobiliária e apuradas por quadra ou logradouro, distrito ou setor, contidas em boletins $(\mathrm{BCl}$ - Boletim de Cadastro Imobiliário) para compor o arquivo cadastral, além de serem representadas cartograficamente. A partir dessas informações os lançamentos do IPTU e das taxas de serviços urbanos deveriam ser realizados.

De um modo geral, a metodologia utilizada pelo Projeto CIATA para o cadastro imobiliário urbano era composta de duas fases: Execução (Fase 1) e; Implantação (Fase 2). A fase de Execução era constituída por 6 etapas: Setorização Fiscal, Levantamento Cadastral, Avaliação de Imóveis, Tratamento da Informação, Lançamento e Arte Final (planta quadra/logradouro), sendo que as 4 primeiras etapas eram realizadas diretamente pelo Serpro e as duas últimas pela Prefeitura, com orientação do Serpro. 
A fase 2 de Implantação constitui-se no momento em que o Projeto faz o repasse de rotinas para a Prefeitura municipal por meio de 3 etapas: atualização do cadastro imobiliário, tratamento e lançamento.

Durante os dois primeiros anos de implantação do Projeto, 1973/74 e 1974/75, trabalhos de levantamento de campo de 20 (vinte) municípios foram realizados por uma empresa de consultoria contratada pelo SERPRO, que tinha a prerrogativa de fazer o processamento dos dados coletados.

A contar de 1975, o SERPRO assume todos os trabalhos de levantamentos de campo, e até o ano de 1976 implanta o Projeto em mais 50 (cinquenta) municípios e presta assistência técnica a mais 20 (vinte) municípios.

Embora a proposta do Projeto CIATA visasse unicamente a melhoria das receitas municipais, a metodologia desenvolvida apresentava semelhanças com a proposta de cadastro apoiada pela SERFHAU, embora o cadastro não fosse pautado pela uniformização das informações imobiliárias, tendo em conta a flexibilidade concedida para que cada município pudesse definir o grupo de informações necessárias ao atendimento da sua finalidade fiscal. (Emplasa, 1992, apud Carneiro, 2003).

Segundo AFONSO et al (1998), no período de 08 (oito) anos de sua vigência (1973/1981), o Projeto Ciata alcançou 769 prefeituras, o que envolveu o cadastramento de mais de 3,5 milhões de unidades imobiliárias. Este alcance trouxe notoriedade e reconhecimento internacional ao Projeto, de forma que sua importância foi reconhecida pelo Banco Mundial em seu relatório mundial de 1988, que o referenciou como paradigma de importância e sucesso na prestação de apoio técnico na área fazendária.

Mesmo com o sucesso do Projeto e a consolidação da descentralização de receitas promovidas no âmbito da Constituição de 1988, o governo federal não manteve o Projeto entre suas prioridades de atuação, tendo em conta a reforma administrativa no âmbito do governo Collor (1990/1992), que extinguiu a Secretaria de Economia e Finanças (SEF), do Ministério da Fazenda, dentre outros órgãos e todas as atividades de pesquisa, coleta, disseminação e análise de informações.

Segundo AFONSO et al (1998), na época, parecia existir uma perversa ideia entre autoridades e técnicos federais de que os governos subnacionais que foram amplamente 
beneficiados com competências, receitas e autonomias tributárias pela reforma de 1988 (e isso em detrimento da União) não teriam mais por que precisar ou ser merecedores de apoio técnico, devendo superar suas dificuldades por conta própria.

A ausência de um marco regulatório para o cadastro urbano, neste caso, fomentou a descontinuidade de políticas públicas, como o apoio aos municípios oferecido por meio do Projeto CIATA, e, por consequência, não obrigou aos governos subsequentes a adotarem medidas que pudessem consolidar o cadastro como ferramenta estruturante para a implementação de políticas tributárias, para o planejamento urbano do município, entre outras políticas correlatas.

\subsection{Iniciativas de apoio financeiro à implementação do cadastro urbano}

Algumas iniciativas de apoio financeiro, no formato oneroso, para a implementação de cadastro nos municípios brasileiros foram criadas pelo governo federal na década de 1990, embora o foco fosse o da modernização da administração municipal, como foi o caso, em 1997, do PMAT - Programa de Modernização das Administrações Tributárias Municipais, gerido pelo BNDES - Banco Nacional de Desenvolvimento Social, por orientação do Ministério do Planejamento e Orçamento, com o objetivo de aumentar o nível de eficiência fiscal dos municípios e reduzir a sua dependência em relação às transferências da União. A estruturação de cadastros imobiliários está, neste caso, entre os itens financiáveis.

O PNAFM - Programa Nacional de Apoio à Administração Fiscal para os Municípios Brasileiros - também foi criado para a melhoria da eficiência administrativa, a racionalização e a transparência na gestão da receita e do gasto público municipal. Operado pela Caixa Econômica Federal, com recursos do Banco Interamericano de Desenvolvimento - BID, de caráter oneroso, o PNAFM designa entre os seus recursos, até $70 \%$ do financiamento para os serviços técnicos de implantação ou atualização cadastral. 


\subsection{A política urbana no Brasil e a importância do cadastro na aplicação dos novos instrumentos urbanísticos}

Apesar de todas as iniciativas do governo federal que fundamentaram o histórico de implementação do cadastro urbano nos municípios brasileiros, de um modo geral, pode-se dizer que é a partir dos desdobramentos da Constituição Federal de 1988 que podemos vislumbrar um cenário favorável à sua normatização, tendo em conta que, pela primeira vez, um marco constitucional brasileiro dedica um capítulo específico à política urbana (artigos 182 e 183), com o objetivo de ordenar o pleno desenvolvimento das funções sociais da cidade, conforme as exigências expressas no plano diretor dos municípios, o que pressupõe a existência de um sistema de informações cadastrais atualizado e compatível com a dinâmica municipal.

Essa afirmação se fortalece por meio das diretrizes gerais para a política urbana pautadas pela Lei no 10.257/2001, denominada Estatuto da Cidade, que ao regulamentar os artigos referentes à política urbana da Constituição Federal, estabelece instrumentos que, para serem implementados, necessitam de dados que só podem ser disponibilizados por meio da organização do cadastro territorial do município.

Além disso, o Estatuto da Cidade estabeleceu a obrigatoriedade de aprovação pelos municípios, num prazo inicial de 5 anos, de planos diretores participativos: “(...) Art. 50. Os Municípios que estejam enquadrados na obrigação prevista nos incisos I e II do caput do art.41 desta Lei e que não tenham plano diretor aprovado na data de entrada em vigor desta Lei deverão aprová-lo até 30 de junho de 2008." (Lei no 10.257/2001, com redação dada pela Lei $n$ o $11.673,2008)$, o que também pressupõe o amplo acesso ao cadastro do município para que o planejamento seja abrangente e efetivo.

De certa forma, podemos assimilar que passamos de um modelo fortemente centralizador ao nível federal, característico do Regime Militar, a um modelo oposto, que concede aos municípios autonomia inédita sobre o desenvolvimento urbano, por meio da elaboração do seu próprio Plano Diretor e da regulação sobre a edificação e o uso e ocupação do solo, conforme a realidade local.

Não obstante a necessidade decorrente do novo regulamento legal e o mérito das iniciativas de implementação do cadastro urbano já arroladas neste artigo, podemos afirmar que a 
existência efetiva de cadastros territoriais ainda não é uma realidade na maioria dos municípios brasileiros.

Neste sentido, cumpre destacar a criação em 2003 do Ministério das Cidades, com o objetivo de "assegurar o acesso à moradia digna, à terra urbanizada, à água potável, ao ambiente saudável e à mobilidade com segurança" (BRASIL, 2004:3) e, sobretudo, para articular uma nova Política Nacional de Desenvolvimento Urbano, pautada pela articulação estruturante entre as políticas setoriais de habitação, saneamento ambiental, mobilidade urbana e de planejamento urbano, por meio de temas estratégicos como gestão democrática, a capacitação de técnicos, gestores municipais e agentes sociais e uma política de informações.

Entre as primeiras ações estruturantes do Ministério das Cidades, destaca-se a criação do Programa Nacional de Capacitação das Cidades - PNCC, com o objetivo de capacitar os técnicos e gestores municipais e agentes sociais para a implementação da nova Política Nacional de Desenvolvimento Urbano.

Um dos primeiros temas articulados e discutidos diretamente no âmbito do PNCC foi o Cadastro Territorial sob uma perspectiva Multifinalitária, seguindo as novas tendências mundiais, no sentido de propor aos municípios a existência de uma base de dados territoriais única para que todos os setores e atores do município a utilizem e construam suas políticas setoriais em torno dela, em especial o seu plano diretor.

Dessa forma, o Cadastro Territorial Urbano começou a ser disseminado como instrumento para a efetividade do processo de planejamento urbano e para a busca da eficiência na gestão municipal não só sob o aspecto financeiro, de arrecadação, mas pela dimensão jurídica, social, ambiental e física que o instrumento pode potencializar na esfera da infraestrutura municipal, colaborando para a efetivação de sua autonomia e para a ampliação da transparência nas ações do poder público, fundamentos essenciais para a construção de uma cidade democrática e com justiça social.

Várias foram as ações de capacitação sobre Cadastro Territorial Multifinalitário realizadas pelo Ministério das Cidades. A metodologia diversificada das ações de capacitação garantiu uma abordagem dialógica sobre os desafios do processo de implementação do CTM, pautados, principalmente, pela ausência de regulamentação na área. 


\subsection{As Diretrizes Nacionais para a Implementação do Cadastro Territorial Multifinalitário} no Brasil

Tendo em conta o diagnóstico de problemas decorrentes da ausência de regulamento para a implementação do cadastro urbano no Brasil, o Ministério das Cidades cria, em 2007, um grupo de trabalho (GT-Cadastro, Portaria no 516, de 16/10/2007, publicada no DOU de 17/10/2007) para estudar a matéria e formular uma proposta de diretrizes para o tema, compatível com as diversas realidades dos municípios brasileiros. O grupo foi protagonizado por especialistas renomados na área, atuantes nas ações de capacitação do PNCC, e representantes das diversas instâncias envolvidas: prefeituras, universidades e parceiros institucionais.

Com o objetivo de validar e aprimorar a proposta de diretrizes elaborada pelo grupo, em 2007 foi organizado, em São Paulo, um Seminário Nacional, que contou com convidados representantes do poder público municipal, estadual e federal de todas as regiões do país, além de professores, mestres e doutores especialistas em cadastro e demais profissionais atuantes na área, como engenheiros agrimensores, cartógrafos entre outros.

A dinâmica de trabalho estruturada durante o referido Seminário permitiu o intercâmbio de ideias e conceitos em torno da proposta apresentada, o que contribuiu para o seu aprimoramento, em especial, em relação ao seu aspecto operacional. Destaque para o apoio do Programa Cidade Brasil, no âmbito da Cooperação Técnica em Desenvolvimento Urbano da Embaixada da França no Brasil, que trouxe especialistas franceses para o aporte da experiência do Cadastro francês, com o objetivo de enriquecer a discussão no âmbito comparativo da experiência internacional, o que rendeu aos componentes do GT-Cadastro um convite à França para conhecimento in loco dos métodos e dispositivos franceses utilizados na administração fundiária e cadastral, o que possibilitou a validação da premissa conceitual das diretrizes propostas pelo grupo e direcionou entendimentos em torno dos aspectos técnicos a serem considerados em todo o processo de implementação de um CTM. Nessa perspectiva, e considerando o então recém-editado Decreto $n \cong 06.666$, de 27/11/2008, que instituiu, na esfera do Poder Executivo federal, a Infraestrutura Nacional de Dados Espaciais - INDE, o Ministério das Cidades submeteu a proposta das Diretrizes para o CTM à 
Comissão Nacional de Cartografia - CONCAR que sugeriu ajustes pertinentes e manifestouse de forma favorável à iniciativa.

De forma a contemplar os entendimentos das diversas instâncias regulamentares, a proposta das Diretrizes para o CTM foi consolidada nos moldes de uma Portaria Ministerial, editada pelo Ministro das Cidades e publicada no Diário Oficial da União: Portaria Ministerial no 511, de 07 de dezembro de 2009, que institui Diretrizes para a Criação, Instituição e Atualização do Cadastro Territorial Multifinalitário (CTM) nos Municípios Brasileiros, DOU de 08 de dezembro de 2009.

Pelo caráter orientador do documento, a Portaria editada não foi compulsória aos municípios brasileiros e o seu aspecto presumidamente generalista permite a sua aplicação em diferentes contextos e realidades municipais.

Em termos de organização, a Portaria foi estruturada em sete capítulos: I - Das Disposições Gerais; II - Do Cadastro Territorial Multifinalitário; III - Da Cartografia Cadastral; IV - Da Gestão e do Financiamento do Cadastro; V - Da Multifinalidade do Cadastro; VI - Da Avaliação de Imóveis; VII - Do Marco Jurídico e Das Disposições Finais.

No primeiro e segundo capítulos da Portaria Ministerial "Das Disposições Gerais" e "Do Cadastro Territorial Multifinalitário" são apresentados os principais conceitos, em conformidade com os melhores sistemas cadastrais no mundo. A parcela cadastral é apresentada como a menor unidade do cadastro a qual deve ser atribuído um código único e estável. A integração sistemática entre o CTM e o Registro de Imóveis (RI) do município é prevista em um Sistema de Cadastro e Registro Territorial (Sicart) e este, quando relacionado aos cadastros temáticos, constitui o Sistema de Informações Territoriais (SIT). Por definição, o CTM e os sistemas de informação dos quais faz parte deve ser multifinalitário para atender às necessidades sociais, ambientais e econômicas da Administração pública e de segurança jurídica da sociedade.

No Capítulo III "Da Cartografia Cadastral” são feitas recomendações básicas às normatizações da Cartografia Nacional, em especial no que se refere à adoção do Sistema Geodésico Brasileiro (SGB), e as recomendações do Instituto Brasileiro de Geografia e Estatística (IBGE) e aos padrões estabelecidos para a Infraestrutura Nacional de Dados Espaciais (INDE), bem como à ordem de preferência dos atributos específicos dos limites 
territoriais. Em relação ao sistema de projeção pelo respectivo órgão normatizador, recomenda-se a adoção do sistema de projeção Universal Transverso de Mercado, até que seja estabelecido um sistema de projeção específico para o cadastro, a ser normatizado pelas instâncias competentes.

De acordo com o Capítulo IV da Portaria, o município será o responsável pelo processo de gestão e financiamento do CTM, com a sugestão de que mantenha uma equipe técnica local capacitada para a atualização contínua do sistema e de que invista parte dos recursos provenientes do incremento de receitas geradas pelo CTM na sua própria sustentabilidade. Outra orientação importante, principalmente para os pequenos municípios, é a possibilidade de redução de custos por meio da constituição de consórcios públicos intermunicipais para a implementação do CTM, conforme a legislação editada sobre a matéria (Lei no 11.107, de 2005, que dispõe sobre normas de contratação de consórcios público e dá outras providências).

No que se refere ao caráter multifinalitário do CTM, no Capítulo V ele é apresentado como um processo evolutivo aberto, de integração gradativa dos diferentes temas e que deve ocorrer ao longo dos anos. No entanto, sua efetivação depende do processo de modelagem inicial de dados, que deve atender às necessidades dos diferentes usuários, com base em um sistema de referência único e um identificador estável para cada parcela.

No Capítulo VI são feitas recomendações referentes à avaliação de imóveis, de modo que este seja um processo técnico e transparente, conforme o que preceitua a Associação Brasileira de Normas Técnicas. Dessa forma, recomenda-se ciclos de 4 (quatro) ou 8 (oito) anos para atualização da planta de valores genéricos, conforme o porte e a dinâmica imobiliária do município, o que possibilitará a obtenção da situação real dos valores de imóveis no mercado, de forma a permitir o fortalecimento da arrecadação local dos tributos imobiliários e a promoção da justiça fiscal e social com o tratamento isonômico dos contribuintes que necessitam de informações claras e precisas sobre os dados do seu imóvel.

No âmbito da estruturação das Diretrizes, o último Capítulo "Do Marco Jurídico e das Disposições Finais" descreve o CTM como sistema integrante do patrimônio público municipal e, portanto, sujeito aos princípios preponderantes da administração pública. São 
arrolados os principais dispositivos legais vigentes diretamente vinculados à existência de um CTM, em especial, os que se referem à implementação dos instrumentos de política urbana previstos no Estatuto da Cidade.

Em 2015, foi apresentado à Câmara dos Deputados o Projeto de Lei no 3876, que "estabelece normas para elaboração do cadastro territorial dos municípios e dá outras providências." (BRASIL, 2015). Esse projeto tem como base o texto da referida Portaria no 511 , com as adequações que se referem basicamente às diferenças entre um documento de caráter orientativo, não obrigatório, e uma lei que estabelece a obrigatoriedade de implementação do cadastro.

\subsection{O Cadastro Urbano no âmbito de um Sistema de Informações Territoriais}

Em 2016 foi publicado o Decreto no 8.764, que institui o Sistema Nacional de Gestão de Informações Territoriais - SINTER, como "ferramenta de gestão pública que integrará, em um banco de dados espaciais, o fluxo dinâmico de dados jurídicos produzidos pelos serviços de registros públicos ao fluxo de dados fiscais, cadastrais e geoespaciais de imóveis urbanos e rurais produzidos pela União, pelos Estados, pelo Distrito Federal e pelos Municípios." (BRASIL, 2016).

O objetivo de tal sistema, cuja gestão é de responsabilidade da Receita Federal do Brasil, é disponibilizar uma plataforma tecnológica capaz de recepcionar informações cadastrais produzidas por municípios, INCRA e outras instituições públicas, bem como acessar as informações registrais, de acordo com as permissões estabelecidas pelas legislações pertinentes.

As normas para que esses dados possam efetivamente ser integrados ao SINTER serão determinadas por manuais operacionais que estão em fase de elaboração, por grupos de trabalho dedicados aos temas específicos.

\subsection{Uma síntese das iniciativas para a implementação de cadastros urbanos}

O quadro 1 apresenta uma síntese das iniciativas relacionadas à implementação de cadastros urbanos no Brasil, ao longo do tempo. 


\section{REPÚBLICA POPULISTA (1945 - 1964)}

- 1946: Nova Constituição Brasileira: designa aos municípios a competência para arrecadação de tributos:

- Amplia-se o processo de municipalização do país

- Municípios organizam os serviços públicos locais

- 1950: Primeiras experiências de Cadastro Técnico Urbano

- Grupo Hollerith: metodologia fotogramétrica no cadastramento de campo, base cartográfica para ampliar as fotografias aéreas

- Cadastro de Curitiba e em mais 40 cidades brasileiras

- 1964: Criação do BNH

DITADURA MILITAR (1964-1985)

- SERFHAU: Financia cadastro para médias e grandes cidades com recursos do BNH

- 1973: Projeto CIATA:

(Implementação experimental em Paraty e pequenos municípios)

- 1977: CIATA aceita municípios de maior porte

- 1981: Fim do Projeto CIATA:

769 municípios contemplados

3,5 milhões de unidades imobiliárias cadastradas

\section{NOVA REPÚBLICA (1985-HOJE)}

- 1997: PMAT: Financia a modernização da administração tributária dos municípios e a implementação de cadastros

- 2001: Estatuto da Cidade

PNAFM: Financia a modernização dos municípios e a implementação de cadastros

- 2003: Ministério das Cidades

2007: Constituição do Grupo de Trabalho em Cadastro

- 2009: Portaria Ministerial no 511/2009 - Institui Diretrizes para o Cadastro Territorial Multifinalitário

- 2015: Projeto de Lei no 3876/2015, que "estabelece normas para elaboração do cadastro territorial dos municípios e dá outras providências."

- 2016: Decreto no 8.764/2016 - Institui o Sistema Nacional de Gestão de Informações Territoriais e regulamenta o disposto no art. 41 da Lei no 11.977, de 7 de julho de 2009.

Quadro 1: O Cadastro Urbano no Brasil - Linha do Tempo

Fonte: elaborado pelos autores

Cabe registrar, ainda, que no âmbito da nova gestão presidencial, a partir de 2019, o Ministério das Cidades foi extinto e a maioria de suas ações foram incorporadas pelo novo Ministério do Desenvolvimento Regional (Decreto no 9.666/2019). Observa-se, pela legislação decorrente, que a Secretaria Nacional de Desenvolvimento Regional e Urbano, por meio do Departamento de Articulação e Gestão do Desenvolvimento Regional e Urbano assumirá a promoção de ações de apoio ao Cadastro, no entanto, com foco nas cidades médias e cidades gêmeas da Faixa de Fronteira: "Art.22. Ao Departamento de Articulação e Gestão do Desenvolvimento Regional e Urbano compete: (...) 
XIX - promover ações de apoio ao Cadastro Multifinalitário para territórios e cidades, com destaque para as cidades médias e cidades gêmeas da Faixa de Fronteira;" (Decreto no. 9.666/2019).

\section{Conclusões}

As diretrizes emanadas do Ministério das Cidades não apresentaram novidades. De fato, o objetivo do documento não foi o de criar algo novo, mas sistematizar as principais questões que envolvem a temática para orientar, de forma clara e precisa, os gestores e técnicos municipais que pretendem implementar um CTM.

Para apresentar as Diretrizes, o Ministério lançou uma história em quadrinhos intitulada “Zeca Dastro e as Diretrizes para o Cadastro Territorial Multifinalitário”, que traduz, de maneira didática e divertida, o empenho dos técnicos municipais nos desafios relativos à construção de um sistema de informações territoriais para atender às demandas variadas das diversas secretarias municipais. A edição da referida história em quadrinhos também foi escolhida como uma forma de homenagear os professores do GT-Cadastro que colaboraram com os estudos para a publicação da Portaria Ministerial, e nas atividades de capacitação em CTM do Programa Nacional de Capacitação das Cidades que subsidiaram empiricamente os encaminhamentos que se seguiram até a edição da Portaria Ministerial. Além disso, cabe registrar que a história em quadrinhos foi editada em inglês, francês e espanhol, o que possibilitou a sua disseminação em outros países, especialmente os da América Latina, servindo de referência para as atividades de formação na área e disseminação da importância do Cadastro na condução de políticas públicas.

Com a missão de complementar os conceitos apresentados, com o aprofundamento necessário referente às suas alternativas de aplicação, o Ministério das Cidades publicou um Manual de Apoio, apresentando exemplos práticos e métodos de trabalho compatíveis com o contexto diversificado dos municípios brasileiros. Sua utilização foi fundamental no processo de divulgação e implementação das Diretrizes elaborado pelo Ministério das Cidades no âmbito do Programa de Apoio à Extensão Universitária (Proext-Cidades), coordenado pelo Programa Nacional de Capacitação das Cidades, com o apoio do Ministério 
da Educação, que viabiliza a participação efetiva de universidades federais de todas as regiões do país na implementação de cursos e atividades de extensão universitária na área.

A aprovação das Diretrizes Nacionais para o CTM pelo Ministério das Cidades, de um modo geral, representou um esforço inicial do governo federal para a regulamentação efetiva do cadastro urbano no Brasil. No entanto, pelo seu caráter voluntário, de não obrigatoriedade por parte dos municípios, teve baixa adesão, apesar de ter se tornado referência de trabalho para os projetos em andamento.

A verdade é que o Brasil precisa de uma Lei para o Cadastro Urbano que possibilite a implementação do cadastro em todos os municípios brasileiros, sem exceção, de forma que esta possa definir sua composição básica, integrações, atribuições efetivas e que conduzam à conformação do direito urbanístico e ao desenvolvimento sustentável dos Municípios.

\section{Referências bibliográficas}

AFONSO, José Roberto et al. Municípios, arrecadação e administração tributária: quebrando tabus. Revista do BNDES, Rio de Janeiro, v. 5, n.10, p. 3-36, 1998.

BRASIL. Lei no 10.257: 2001. Estatuto da Cidade. Brasil. 2001

BRASIL. Ministério das Cidades. Caderno 1. Brasília: Ministério das Cidades, 2004.

BRASIL. Projeto de Lei no 3.876/2015. Estabelece critérios para a elaboração e manutenção do cadastro territorial dos Municípios e dá outras providências. Câmara dos Deputados. Brasília (DF)

BRASIL. Decreto no 8.764: 2016. Institui o Sistema Nacional de Gestão de Informações Territoriais e regulamenta o disposto no art. 41 da Lei no 11.977, de 7 de julho de 2009. Brasil. 2016

BRASIL: Ministério das Cidades. Diretrizes para a Criação, Instituição e Atualização do Cadastro Territorial Multifinalitário nos Municípios Brasileiros - Manual de Apoio. (Org.) Cunha, Eglaisa M. P. e ERBA, Diego A. Brasília. 2010.

BRASIL. Ministério da Fazenda. Projeto Ciata. Anteprojeto municípios de pequeno Porte. Serpro. 1980

BRASIL. Ministério da Fazenda. Projeto Ciata. Ciata e grandes municípios 77/78. Serpro. 1980

BRASIL. Ministério da Fazenda. Projeto Ciata, pequenos municípios. Proposta para Execução 1978, 1979. Serpro. 1980

BRASIL. Ministério da Fazenda. Projeto Projeto Ciata. Manual do supervisor. Serpro. 1980

BRASIL. Ministério da Fazenda. Projeto Ciata. Manual do cadastro imobiliário. Serpro. 1980

BRASIL. Ministério da Fazenda. A Presença do Ministério da Fazenda Junto aos Estados e Municípios - 50 anos de Assistência Técnica. Revista de Finanças Públicas, Brasília: Secretaria de Economia e Finanças/MF, n. 347, p. 4-27, jul./set; 1981.

CARNEIRO, Andrea F.T. Cadastro imobiliário e registro de imóveis - A Lei no 10.267/2001, Decreto no 4.449/2002 e Atos Normativos do INCRA. 1. ed. Porto Alegre: Sérgio Antonio Fabris, 2003. v. 1. 272p . 
CIGOLINI, Adilar Antonio. Território e criação de municípios no Brasil: Uma abordagem histórico-geográfica sobre a compartimentação do espaço. Tese (doutorado). UFSC, 2009.

MOTA, Juliana Costa. Uma Análise da Criação e da Atuação do SERFHAU. Anais do XII Encontro da Associação Nacional de Pós-Graduação e Pesquisa em Planejamento Urbano e Regional. Belém. 2007.

SILVA, Tarcísio Ferreira. Um Conceito de Cadastro Metropolitano. Dissertação de Mestrado. UFPR, 1979.

VIZIOLI, S. H. T. Planejamento Urbano no Brasil: a experiência do SERFHAU enquanto órgão federal de planejamento integrado ao desenvolvimento nacional. Dissertação de Mestrado, FAU-USP, 1998. 